\title{
Outcomes in Anterior Cruciate Ligament Reconstruction Surgery
}

\author{
Mihai Roman', Radu Prejbeanu², Andrei-Marian Feier ${ }^{3}$, Octav Russu $^{3}$, Adrian Todor ${ }^{4}$, Vlad

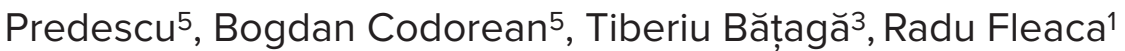 \\ 1 "Victor Papillan" Faculty of Medicine, "Lucian Blaga” University, Sibiu, Romania \\ 2 "Victor Babeș" University of Medicine and Pharmacy, Timișoara, Romania \\ 3 University of Medicine and Pharmacy, Tîrgu Mureș, Romania \\ 4 "Iuliu Hațieganu" University of Medicine and Pharmacy, Cluj-Napoca, Romania \\ 5 "Carol Davila" University of Medicine and Pharmacy, Bucharest, Romania
}

\section{CORRESPONDENCE}

\section{Adrian Todor}

Str. Emil Isac nr. 13

400023 Cluj-Napoca, Romania

Tel: +40 264406843

E-mail: adi.todor@yahoo.com
Mihai Roman • Str. Lucian Blaga nr. 2A, 550169 Sibiu, Romania. Tel: +40 269212 320, E-mail: mihaidanroman@yahoo.com

Andrei-Marian Feier • Str. Gheorghe Marinescu nr. 38, 540139 Tîrgu Mureș, Romania. Tel: +40 265215 551, E-mail: andreifeier@gmx.com

Radu Prejbeanu • P-ța Eftimie Murgu nr. 2, 300041 Timișoara, Romania. Tel: +40 256204 400, E-mail: raduprejbeanu@gmail.com

Octav Russu • Str. Gheorghe Marinescu nr. 38 , 540139 Tîrgu Mureș, Romania. Tel: +40 265215 551, E-mail: octav@genunchi.ro

Adrian Todor • Str. Emil Isac nr. 13, 400023 ClujNapoca, Romania. Tel: +40 264406 843, E-mail: adi. todor@yahoo.com

Vlad Predescu • B-dul Eroii Sanitari nr. 8, 050474 Bucuresti, Romania. Tel: +40 213180 719, E-mail: vladpredescu001@gmail.com

Bogdan Codorean • B-dul Eroii Sanitari nr. 8, 050474 București, Romania. Tel: +40 213180 719, E-mail: dr.codorean@traumatologie-sportiva.ro

Tiberiu Bățagă • Str. Gheorghe Marinescu nr. 38 540139 Tîrgu Mureș, Romania, E-mail: tbataga@ gmail.com

Radu Fleaca • Str. Lucian Blaga nr. 2A, 550169 Sibiu, Romania. Tel: +40 269212 320, E-mail: rfleaca@ yahoo.com

\begin{abstract}
Improving the outcomes in reconstructive surgery of the anterior cruciate ligament $(\mathrm{ACL})$ requires a rigorous and permanent assessment of specific parameters. Therefore, we can increase the degree of reproducibility of the procedure and identify particular aspects in order to achieve an adequate and individualized therapeutic approach for each case. In order to accomplish this goal, the use of complex means (scores) of quantifying results is required. That includes objective means of verifying the parameters in knee surgery, and a subjective evaluation of the patient in order to compare the results.
\end{abstract}

Keywords: anterior cruciate ligament, knee, clinical score, pivot-shift, arthroscopy

\section{INTRODUCTION}

The evaluation activity that follows surgical anterior cruciate ligament (ACL) reconstruction is essential for improving outcomes, reducing complications, and procedure optimization. Conclusively, it increases the quality of care in favor of operated patients. Postoperative knee function evaluation is important in order to appreciate the evolution of the patient, for research purposes, and also for quality analysis and improvement of future therapeutic procedures. When assessing the results, one must take into account the prognostic factors related to each individual (comorbidities, associated knee injuries, etc.). First, intraoperative assessment is necessary in order to establish the knee injury extent and the quality of the ACL reconstruction. Postoperatively, the patient's evolution is evaluated, and aims to guide its recovery using standardized protocols that are well adapted to the particularities of each case. 


\section{OUTCOME EVALUATION POSSIBILITIES - LITERATURE REVIEW}

In order to document and quantify the evolution of postoperative status, clinical scores (patient "subjective" or surgeon "objective"), evaluation imaging (MRI, radiography), evaluation of biomechanics, and return to sport (RTS) are assessed - especially for athletes.

The combined use of the mentioned scores is considered useful. Anteroposterior and rotational stability, articular effusion, mobility and muscle strength might be of great interest for the surgeon; for the patient pain, function, quality of life and activity level are of vast importance. In the last 20 years this approach has virtually changed the paradigm in measuring the success of ACL reconstruction from a strictly clinical and imaging evaluation to patient assessment-centered evaluation. Clinical and functional tests are important indicators of knee function and therapeutic progress when determining and assessing the patient's physical capacity, and can lead to a transition towards a higher level in terms of physical activity.

Unfortunately, a correlation between objective assessment (goniometer KT1000) and reported patient outcomes (PROs) is not always found. ${ }^{1}$

Preoperative evaluation of the patient is essential in order to reduce potential complications. Complete diagnosis and " 0 point" is established to which the subsequent follow-up is compared. Patient particularities and characteristics are always evaluated (gender, age, personality, level of physical activity - professional/recreational, expectation level, a desire to RTS and associated pathologies). The results after ACL reconstruction significantly depend on factors that can be influenced or improved - the quality of the surgery and recovery - , and also on the factors that can not be changed - everything that is related to patient. It is known that gender plays a role in the subjective assessment of the results after ACL reconstruction. Outcomes are inferior in women even if the objective assessment shows no significant differences. ${ }^{2}$ There are certain factors that have prognostic value in terms of results after ACL reconstruction. These include: age, sex, body mass index, smoking, other physical problems, preoperative physical status, healing state after the knee injury, the time between injury and surgery and associated lesions (meniscus, cartilage etc.). Although these prognostic factors have proven their influence on the final results, it does not completely explain the variability of knee function and recovery after ACL reconstruction.

Intraoperative assessment comprises verifying and recording if the graft is adequate, properly positioned, shows no impingement with a secure fixation, and if any associated pathology exists. If, for example, full mobility is not achieved intraoperatively, it is unlikely to be achieved after complete recovery. Also, it is important to know that immediate forced extension may affect the graft. Postoperative assessment includes: walking, subjective status, patient pain, muscles (volume, strength, control), inflammation (articular effusion), mobility (range of motion), stability (Lachman, pivot-shift) at set intervals (2 weeks 6 weeks -3 months -6 months -1 year -2 years -5 years). The most frequently used scores to assess knee function are: Lysholm, Tegner, KOOS and IKDC.

The Lysholm score was created in 1970, published in 1982 , revised in 1985, and tested (validated) in 2006, measuring the patient's disability, his perception about knee function and daily activities. It represents a subjective assessment conducted by the examiner, containing 8 questions ( 25 points/question) with a maximum result of 100 points. The results are assessed as follows: $>90$ points $=$ excellent; $84-90$ points = good; $65-83$ points = average; $<65=$ poor. ${ }^{3,4}$ It was commonly used in most ACL studies in the past 25 years, and it is considered the gold standard in assessing this type of reconstruction.

The Tegner activity score was published in 1985 , and is widely used today. It is a standardized method for grading physical activities and sports, and fulfills the final form of the Lysholm score. Its structure is grounded on the remark that functional limitations of the Lysholm score are masked by the reduced level of activity. Moreover, it describes the level of intensity in everyday recreational and sports activities. It can be filled by the patient in approximately $5 \mathrm{~min}$ utes. The patient is able to choose the level of participation that best describes the current level of activity on a scale from 1 to $10 .^{3}$

The KOOS score (Knee Osteoarthritis Outcome Score and Injury), published in 1998, measures the opinion of the patient's knee on short term or long term. It includes 5 areas: 1) pain (frequency and severity during functional activities); 2) other symptoms (swelling, stiffness, blockage); 3) function in everyday activities; 4) function in sports and recreational activities; 5) knee-related quality of life - QOL. It is dominated by osteoarthritis (3/5 subscales), ACL, meniscus, cartilage, etc. It is a score based on subjective self-assessment, and requires approximately 10 minutes to complete. The calculated points start at 0 , which means severe damage to the knee, and reach $100=$ "no problem". It is commonly used in research, databases, clinical activity, registers (e.g. Scandinavian registers). ${ }^{3,5}$

The IKDC 2000 score (International Knee Documentation Committee Knee ligament outcome guide) is de- 
signed to detect improvement or deterioration of the knee. It is often used in evaluating ligament injuries, meniscal lesions, cartilage lesions and patello-femoral pain. It is divided into three main areas: 1) symptoms (pain, stiffness, swelling, blockage, instability); 2) sports and recreational; 3) current knee status. ${ }^{6}$

Antero-posterior knee laxity is assessed using the Lachman test at 20 degrees of flexion, and drawer test at 70 degrees of flexion. The examination is always compared to the contralateral knee. The results are quantified using special devices such as the KT-1000 arthrometer and Rolimeter.

Rotational laxity is assessed using the pivot-shift test. It has a high variability, and its results depend on the examiner. As mentioned before, the test should be performed in comparison with the normal contralateral knee. A predictive value of the initial pivot-shift test is commonly discussed on the literature, meaning that inferior results were found when a very marked pivot-shift was identified. Recently, there is a growing interest about quantifying the pivot-shift test by measuring tibial acceleration and translation using accelerometers and special software. There are iOS compatible applications that allow the quantification of the pivot-shift test. ${ }^{7,8}$

The mobility of the knee is one of the important postoperative parameters, and the assessment should always be performed compared to the contralateral knee (individualized). Seven to seventeen per cent of patients that underwent ACL reconstruction have various deficient mobility complaints. ${ }^{9}$ Extension deficit is more severe and harder to treat than flexion deficit. Normal extension is on average 5 degrees of hyperextension (DeCarlo, Sell). A deficit of 3-5 degrees has a significant impact on patient satisfaction, and promotes progression to osteoarthritis, affects walking, muscle activity and joint kinematics. ${ }^{10}$ Normal flexion is 140-143 degrees. Flexion deficit is better tolerated than extension, and the impact is minimal when walking. At higher values of deficit, certain difficulty arises when going down stairs or squatting. The single-leg hop test evaluates the recovery, and recommends subsequent management. The test is used in later stages of rehabilitation. ${ }^{11,12}$ It is based on the following idea: it assesses the stability of the knee when jumping and landing, and simulates certain movements required to RTS. The Symmetry Index represents the hop distance test between the two knees (injured knee vs. healthy), and is used in performance assessment. ${ }^{13}$ It has a certain limited use. A reduced performance of the healthy knee may "exaggerate" the estimated return-tosports time. ${ }^{14}$ RTS is an indicator that measures the return to sports activities before the trauma. Eighty-two per cent of the patients return to sports $(4 / 5) ; 63 \%$ return to pre-injury level of sports and activity (2/3); $55 \%$ return to competitive sports (1/2); $90 \%$ of knee function was normal or near normal. A higher rate of RTS was found when assessing professional sport patients versus recreational ones. Among the causes that prevent RTS, the following should be mentioned: suboptimal surgery, poor postoperative recovery, undervaluation of patient's psychosocial factors and fear of re-injury. ${ }^{15}$ ACL re-rupture is often a career-ending condition, and it should be avoided at any cost. The risk of rupture at 5 years is $5.8 \%$, and the risk of contrala-teral ACL rupture at 5 years is $11.8 \%$. There are several risk factors for an ACL injury: young patients (under 20 years), family history of ACL rupture, and the first year after surgery. ${ }^{16}$ The consensus agreement established in Pittsburgh in 2011 states that early RTS may expose the athlete to a higher risk of re-rupture, and that is the reason it should be extended to at least 9 months. It is known that the graft goes through a phase in which its resistance decreases ( 6 weeks to 3 months), and its maturation process evolves slowly. ${ }^{17}$

Osteoarthritis after ACL rupture has an incidence of $0-13 \%$ at 5 years in cases of isolated ACL rupture, and $21-48 \%$ at 5 years if ACL tear is associated with other injuries. ${ }^{18} \mathrm{~A}$ major study conducted by Leo Pinczowski evaluated the outcomes 15 years after ACL reconstruction using "hamstring" tendons for isolated ACL ruptures. The study showed that osteoarthritis after ACL is difficult to assess, and that there are multiple factors contributing to osteoarthritis (education level, various surgical techniques - high variability, associated lesions). The study results showed that if the graft is intact, the incidence of mild or severe osteoarthritis is relatively low (7\%). If the ACL graft is torn, arthritis patients will develop moderate or severe osteoarthritis in a significantly higher percentage (17\%). The conclusion of the presented study was that ACL reconstruction does not cause osteoarthritis, but has a protective effect on the joint. ${ }^{17}$

\section{CONCLUSIONS}

In conclusion, we can affirm that ACL reconstruction yields good results if correct indications are established, if the surgical technique is accurately performed, and if the appropriate rehabilitation program is respected. Ongoing assessment of the results is critical for improving therapeutic performance. ACL reconstruction results depend on the quality of successive decisions - from the moment of diagnosis until the end of recovery. Results assessment is based on a set of objective and subjective criteria, and patient opinion also plays a major role. RTS hangs on many 
factors, and surgery is just a link in a long chain of diagnostic and therapeutic actions.

\section{CONFLICT OF INTEREST}

Nothing to declare.

\section{REFERENCES}

1. Logerstedt D, Grindem H, Lynch A, et al. Single-legged Hop Tests as Predictors of Self-Reported Knee Function After Anterior Cruciate Ligament Reconstruction: The Delaware-Oslo ACL Cohort Study. Am J Sports Med. 2012;40:2348-2356

2. Tan SH, Lau BP, Khin LW, et al. The Importance of Patient Sex in the Outcomes of Anterior Cruciate Ligament Reconstructions: A Systematic Review and Meta-analysis. Am J Sports Med. 2016;44:242-254.

3. Tegner Y, Lysholm J. Rating systems in the evaluation of knee ligament injuries. Clin Orthop Relat Res. 1985;(198):43-49.

4. Mitsou A, Vallianatos P, Piskopakis N, et al. Anterior cruciate ligament reconstruction by over-the-top repair combined with popliteus tendon plasty. J Bone Joint Surg Br. 1990;72:398-404

5. Roos EM, Roos HP, Lohmander LS, Ekdahl C, Beynnon BD. Knee Injury and Osteoarthritis Outcome Score (KOOS) - development of a selfadministered outcome measure. J Orthop Sports Phys Ther. 1998;28:8896.

6. Irrgang JJ, Anderson AF, Boland AL, et al. Development and validation of the International Knee Documentation Committee subjective knee form. Am J Sports Med. 2001;29:600-613.

7. Zaffagnini S, Lopomo N, Signorelli C, et al. Inertial sensors to quantify the pivot shift test in the treatment of anterior cruciate ligament injury. Joints. 2014;2:124-129.
8. Hoshino Y, Araujo P, Ahldén M, et al. Quantitative evaluation of the pivot shift by image analysis using the iPad. Knee Surg Sports Traumato Arthrosc. 2013:21:975-980

9. Carneiro M, Nakama GY, Malheiros Luzo MV. Loss of Extension after Anterior Cruciate Ligament Reconstruction Treated with Arthroscopic Posteromedial Capsulotomy. Ann Sports Med Res. 2015;2:1013.

10. De Carlo MS, Sell KE. The effects of the number and frequency of physical therapy treatments on selected outcomes of treatment in patients with anterior cruciate ligament reconstruction. J Orthop Sports Phys Ther. 1997;26:332-339.

11. Arden CL. Webster KE, Taylor NF, Feller JA. Return to sport following ACL-R surgery: A systematic review and meta-analysis of the state of play. Br J Sports Med. 2011;45:596-606.

12. Grindem $H$, Logerstedt $D$, Eitzen I, et al. Single-legged hop tests as predictors of self-reported knee function in nonoperatively treated individuals with anterior cruciate ligament injury. Am J Sports Med. 2011;39:2347-2354

13. Engelen-van Melick N, Cingel REH, Tijssen MPW, Nijhuis-van der Sanden MWG. Assessment of functional performance after anterior cruciate ligament reconstruction: a systematic review of measurement procedures. Knee Surg Sports Traumatol Arthrosc. 2012;21:869-879.

14. Button K, van Deursen R, Price P. Measurement of functional recovery in individuals with acute anterior cruciate ligament rupture. $\mathrm{Br} J$ Sports Med. 2005;39:866-871.

15. Ardern CL, Taylor NF, Feller JA, et al. Fifty-five Per Cent Return to Competitive Sport Following Anterior Cruciate Ligament Reconstruction Surgery. Br J Sports Med. 2014;48:1543-1552.

16. Wright RW, Magnussen RA, Dunn WR, et al. I psilateral graft and contralateral $A C L$ rupture at five years or more following $A C L$ reconstruction: a systematic review. J Bone Joint Surg Am. 2011;93:1159-1165.

17. Lynch AD, Logerstedt DS, Grindem H, et al. Consensus criteria for defining 'successful outcome' after ACL injury and reconstruction: a Delaware-Oslo ACL cohort investigation. Br J Sports Med. 2015;49:335-342.

18. Øiestad BE, Engebretsen L, Storheim K, et al. Review Knee osteoarthritis after anterior cruciate ligament injury: a systematic review. Am J Sports Med. 2009;37:1434-1443. 